\title{
Teoria marxista da dependência: a contribuição teórica de Ruy Mauro Marini
}

\author{
Marxist dependency theory: the theoretical contribution by Ruy Mauro Marini
}

Pedro Henrique Evangelista Duarte (1)

(1) Universidade Federal de Goiás

\begin{abstract}
The aim of this paper is to discuss the two most important cathegories proposed by Ruy Mauro Marini - the workforce superexploitation and the subimperialism - and its relevance for understanding the especificities of the capitalist development in the peripheral and dependent latin-american countries, considering the role played for those countries in the internacional divison of labour. Furthermore, we will highlight the importance of the political aspects in Marini's theory, and how those two cathegories are central in his critical interpretation on the political, economic and social problems of latin-american countries. Problems which could be solved only from the overcoming of the capitalist mode of production.
\end{abstract}

\section{Keywords}

marxist theory of dependency, dependent capitalism, peripheral capitalism, workforce superexploitation, subimperialism.

JEL Codes B14, B24, B51, O54.

\section{Resumo}

O presente artigo tem como objetivo retomar duas categorias formuladas por Ruy Mauro Marini superexploração da força de trabalho e subimperialismo - e suas respectivas articulações na compreensão das especificidades do desenvolvimento capitalista nos países periféricos e dependentes latino-americanos, a partir da forma particular que assumem na divisão internacional do trabalho. Adicionalmente, serão pontuados alguns elementos sobre a importância do aspecto político na obra de Marini, e como as supracitadas categorias são centrais na articulação de sua intepretação acerca dos problemas políticos, econômicos e sociais da América Latina, os quais poderiam ser equacionados somente a partir da própria superação do modo de produção capitalista.

\section{Palavras-chave}

teoria marxista da dependência, capitalismo dependente, capitalismo periférico, superexploração da força de trabalho, subimperialismo.

Códigos JEL B14, B24, B51, O54. 


\section{Introdução}

Ruy Mauro Marini (1932-1997) foi um intelectual brasileiro que compôs um dos mais importantes grupos teórico-político da década de 1960 formado por Vânia Bambirra, Theotônio dos Santos, André Gunder Frank e outros -, dedicando-se à formulação de uma nova interpretação a respeito das especificidades do desenvolvimento capitalista na América Latina. Para além do campo teórico, esses intelectuais tinham uma preocupação central com a prática política, enquanto instrumento essencial para a superação dos gargalos ao desenvolvimento social, próprios do sistema capitalista de produção. Assim, a dedicação desse grupo de intelectuais à tentativa de propor uma interpretação do capitalismo latino-americano tinha o objetivo de construir fundamentos teóricos para a prática política da esquerda, a qual permitisse a compreensão dos processos econômicos, sociais e políticos que resultavam na conformação de uma estrutura econômica fundada na consolidação das relações de dependência. As teses elaboradas por esse grupo resultaram na criação da teoria marxista da dependência (TMD).

A TMD partia de um diagnóstico similar ao formulado pela teoria estruturalista da Comissão Econômica para a América Latina e Caribe (CEPAL) ${ }^{1}$ para a explicação dos entraves ao desenvolvimento na América Latina. No entanto, tendo como fundamento teórico a teoria marxista do valor, os autores vinculados à TMD percebiam o subdesenvolvimento como uma forma própria e específica de capitalismo, resultado da estrutura e da expansão do capitalismo em nível internacional e, portanto, fruto da difusão do imperialismo e da função ocupada pelos países latino-americanos na divisão internacional do trabalho. Enquanto forma própria de capitalismo, a superação da condição dependente e periférica não poderia se dar nos marcos do sistema capitalista, de modo que a crítica à condição dependente passaria pela crítica ao sistema capitalista, fator que justifica a centralidade da luta política na TMD.

1 A teoria estruturalista da CEPAL busca nos efeitos do intercâmbio desigual e da transferência de renda periferia-centro a explicação para os problemas do subdesenvolvimento na América Latina. A articulação ao mercado internacional como fornecedor de produtos primários e a dependência da importação de produtos industrializados criava entraves ao desenvolvimento da região, para o que seria necessária a instalação do setor industrial, a partir da articulação de poupança via Estado, como forma de dar cabo ao pleno desenvolvimento da região (Bielschowsky, 2000). 
O objeto dessa nova formulação teórica era a compreensão do processo de formação socioeconômico na América Latina a partir de sua integração subordinada à economia capitalista mundial. A partir dessa integração, observava-se uma relação desigual de controle hegemônico dos mercados e fatores de produção por parte dos países centrais, que resultava numa permanente transferência de renda no sentido periferia-centro. Essa relação seria desigual na medida em que o avanço econômico e social de determinadas regiões - os países centrais - ocorreria às expensas da intensificação das relações de subordinação de outras regiões - os países periféricos. De acordo com Marini (1968), a incursão imperialista nas economias latino-americanas deformou o desenvolvimento histórico dos países da região, impossibilitando o desenvolvimento do modo de produção capitalista nos moldes verificados nos países centrais.

Para adentrar de maneira mais detalhada na contribuição elaborada por Ruy Marini acerca do debate teórico e político na América Latina, o presente texto irá tratar das duas categorias centrais formuladas pelo autor: a superexploração da força de trabalho e o subimperialismo. Ao apresentar as categorias, pretende-se evidenciar não apenas suas respectivas importâncias na compreensão dos efeitos do desdobramento do modo de produção capitalista na América Latina, mas também como a sua articulação teórica se revela como elemento fundamental na proposição do debate político presente na tese do autor. Nesse sentido, o objetivo do texto é mostrar como os aspectos teóricos e políticos estão articulados na obra do autor - ou, mais objetivamente, a proposição de formulações teóricas para o fornecimento de instrumentos de compreensão da realidade que fundamentem a prática política.

Assim, entende-se que as novas proposições categóricas introduzidas por Marini têm duplo objetivo. De um lado, propor um entendimento histórico das especificidades do capitalismo periférico e dependente de maneira descolada das teses clássicas do desenvolvimento, a partir da percepção de que, por suas particularidades históricas, o capitalismo na América Latina possui uma configuração distinta daquela verificada nos países centrais, ainda que prevaleçam as leis de tendência do modo de produção capitalista. De outro lado - e em decorrência do primeiro aspecto - como se pode propor uma análise política do processo econômico na América Latina, dado que tais categorias são fundamentais no entendimento de que a condição periférica e dependente é resultado da forma que assume o 
avanço do modo de produção capitalista em nível mundial. Desse modo, sua superação não pode ser percebida nos marcos do sistema capitalista, senão na superação do próprio capitalismo. Nesse sentido, a proposição teórica forneceria o substrato para a organização da prática política, voltada à crítica ao sistema capitalista de produção.

Para apresentar a formulação teórica dessas categorias, suas respectivas articulações e a forma como são elaboradas para dar suporte à prática política proposta pelo autor, este artigo está dividido em duas seções, além desta introdução. Na primeira seção, serão abordados os aspectos teóricos das duas categorias em análise. Na segunda, será apresentada a forma como tais categorias se articulam com o debate no campo político.

\section{Fundamentação teórico-histórica das categorias²}

A fundamentação teórica das categorias superexploração da força de trabalho e subimperialismo se relaciona de forma estreita à compreensão que o autor tinha do modo através do qual se consolidou o sistema capitalista de produção nas regiões periféricas. Marini não estabelecia uma visão positiva acerca do capitalismo, percebendo neste a reunião de mecanismos que imputava ao avanço de determinadas regiões a ocorrência de dependência em outras. É por isso que compreender as categorias supracitadas perpassa pelo entendimento da expansão da economia capitalista em nível internacional, do tipo de capitalismo que se desenvolveu nas economias dependentes e periféricas, e pela consolidação das relações centro-periferia

2 Ainda que não seja objetivo central deste texto, importa destacar que a teoria da dependência foi tema de controvérsias no campo da teoria econômica e social, especialmente no que diz respeito à interpretação proposta pelos autores em sua versão marxista. Entre essas, aquela proposta por Cardoso e Faletto (2004), segundo a qual a condição dependente não necessariamente impossibilitaria o desenvolvimento dos países periféricos, dada a possibilidade de associação ao capital externo como forma de promover o avanço dos setores produtivos internos - razão pela qual a mesma ficou conhecida como "capitalismo dependente-associado". Por sua vez, Fontes (2010) propõe uma leitura crítica acerca da tese do subimperialismo, ao indicar que países como o Brasil, ainda que avancem no processo de transnacionalização de suas empresas, o fazem basicamente no setor primário, como exportador de commodities e sem a constituição de um capital financeiro nacional. Tal condição contrariaria a tese de Lênin, segundo a qual os países do centro se tornaram imperialistas ao alcançarem um patamar elevado de desenvolvimento muito elevado, que pode ser identificado à associação entre capital financeiro, poder militar, moeda forte, domínio do processo de inovação científico-ideológico e capacidade de determinar os rumos da economia mundial - características que não são observadas no Brasil. 
a partir da difusão do imperialismo como nova fase do sistema capitalista de produção.

Se é certo dizer que o diagnóstico da $T M D$ se assemelha àquele formulado pela teoria cepalina, diferentes são as percepções acerca dos efeitos da industrialização na região. Tomado enquanto processo que permitiria, através da transição da indústria leve para a indústria de base, o equacionamento dos problemas estruturais da região, o processo de substituição de importações acabou por agudizar algumas das contradições já presentes na região, ao contrário de romper com as bases da dependência externa. Assim, os próprios fatores históricos mostraram que a industrialização, de fato, não seria o caminho viável para a superação da condição dependente. É a luz desses fatos que as categorias elaboradas por Marini devem ser analisadas.

\subsection{Superexploração da força de trabalho}

Marini (2000) argumenta as relações comerciais dos países latino-americanos com os países capitalistas centrais, baseada na deterioração dos termos de intercâmbio, se converteu numa permanente espiral de endividamento, onde os déficits no balanço de pagamentos eram sucessivamente cobertos com novos empréstimos externos. Dessa estrutura, se estabelece o processo de transferência de renda - tanto do ponto de vista comercial quanto do ponto de vista financeiro -, fator determinante no curso do desenvolvimento posterior da região, especificamente por impor mecanismos nos quais o mais-valor gerado nos países periféricos era transferido e acumulado nos países centrais. Em decorrência desses processos que se estabelece a dependência,

(...) uma relação de subordinação entre nações formalmente independentes, em cujo âmbito as relações de produção das nações subordinadas são modificadas ou recriadas para assegurar a reprodução ampliada da dependência (Marini, 2000, p. 109)..$^{3}$

3 Em sentido complementar, Bambirra (1978, p. 41) dizia que "[dependencia] no es meramente un fenómeno de relaciones internacionales, de intercambio comercial desfavorable a los países poco desarrollados; sino que son relaciones internas, que configuran una estructura económico-social cuyo carácter y dinámica están condicionados por la subyugación, explotación y dominación imperialista. Las consecuencias de orden político que emergen de este análisis son muy claras: lãs burguesias dependientes no tienen condiciones de enfrentarse al imperialismo y de promover un desarrollo autónomo." Para Santos (1978, p. 37), 
É assim que a forma pela qual a América Latina se insere no comércio internacional se firma como elemento central no desenvolvimento industrial dos países centrais. A especialização pela qual os países centrais necessitaram passar, em seus processos de industrialização, pressupunha não apenas o bloqueio da produção agrícola - como forma de canalizar os recursos para a indústria - mas também de encontrar fontes provedoras dos bens primários necessários ao funcionamento da indústria. Tal dinâmica, ao promover o aprofundamento da divisão internacional do trabalho, solidificou a especialização dos países centrais como produtores mundiais de manufaturas. De modo que, mais do que responder às necessidades físicas induzidas pela acumulação nos países industriais,

(...) a participação da América Latina no mercado mundial contribuirá para que o eixo da acumulação na economia industrial se desloque da produção de mais-valia absoluta à da mais-valia relativa, isto é, que a acumulação passe a depender mais do aumento da capacidade produtiva do trabalho do que simplesmente da exploração do trabalhador (Marini, 2000, p. 112-113).

$\mathrm{O}$ autor pretende demonstrar que, para se processar o deslocamento do eixo de acumulação do mais-valor absoluto para o mais-valor relativo, seria necessária a alteração na relação entre tempo de trabalho necessário e tempo de trabalho excedente e, para isso, a redução do valor da força de trabalho. Como o valor da força de trabalho é determinado, basicamente, pelos chamados bens-salário, cuja composição é prioritariamente de bens primários, as possibilidades de alteração do valor da força de trabalho estariam estritamente vinculadas à oferta mundial desses bens, realizada pelas economias capitalistas periféricas. Assim, a ampliação da oferta desses bens e a redução de seus preços no comércio internacional conduziriam à redução do valor da força de trabalho nos países industrializados, permitindo que o incremento de sua produtividade se convertesse em cotas cada vez mais elevadas de mais-valor - ficando determinada a forma pela qual as exportações latino-americanas contribuíam para a modificação do eixo de acumulação nos países centrais. No entanto, se a dinâmica do comércio internacional poderia resultar na redução dos valores dos bens primários,

\footnotetext{
“(...) la dependencia es una característica intrínseca del sistema socioeconómico de los países subdesarrollados [que] se caracteriza por la existencia de una interdependencia creciente entre las economias nacionales a escala mundial bajo la hegemonía de uno o varios centros dominantes que transforman este desarrollo en acumulación de riqueza y poder para ellos en detrimento de las amplias mayorías mundiales. (...) [La] face interna no es, pues, una consecuencia de factores externos, sino que es su própria manera - el modo dependiente de participar de estes proceso de desarrollo de la economía mundial capitalista."
} 
à medida da ampliação de sua oferta, o mesmo não ocorria com o valor dos bens manufaturados, cujo valor era menos elástico e, portanto, menos suscetível a redução. Ao estabelecer a troca entre bens cujos valores possuem dinâmicas contrapostas, o comércio centro-periferia gradualmente se caracterizaria pelo intercâmbio desigual, vale dizer, troca de bens com distintas composições de valores.

Assim, o resultado do intercâmbio desigual seria a transferência de renda entre as diferentes esferas produtivas e/ou países, de modo que os valores gerados nas esferas dependentes fossem transferidos e acumulados nas esferas detentoras de tecnologias e monopólios, criando a necessidade de reposição desse capital como forma de manter o processo interno de reprodução.

O que importa observar é que, para incrementar a massa de valor produzida, o capitalista deve necessariamente lançar mão de uma maior exploração do trabatho, seja através do aumento de sua intensidade, seja mediante a prolongação da jornada de trabalho, seja finalmente combinando os dois procedimentos (Marini, 2000, p. 121-122).

O ponto-chave é que a compensação dessa transferência, realizada no plano interno de cada economia periférica, não poderia ocorrer via aumento da produtividade, fosse porque as nações periféricas não conseguiam desenvolver uma base técnica que permitisse a ampliação do mais-valor via aumentos de produtividade, fosse porque o aumento da produtividade, por si só, não garantiria o aumento da cota de mais-valor, para o que era primordial a redução do valor da força de trabalho. Por isso somente através do aumento dos graus de exploração do trabalho seriam possíveis aos países periféricos a ampliação do mais-valor e a compensação dos valores transferidos ao centro.

Seriam três os principais mecanismos, atuando de forma isolada ou combinada, através dos quais as nações periféricas conseguiriam ampliar o mais-valor como forma de efetivar o processo de acumulação capitalista. O primeiro seria o aumento da intensidade do trabalho, através do qual o trabalhador passa a produzir, numa mesma jornada de trabalho, uma quantidade de bens superior à que produzia nas condições anteriores. O segundo seria a prolongação da jornada de trabalho, de forma a acrescentar o tempo de trabalho excedente em relação ao tempo de trabalho necessário - ou seja, amplia-se o período de produção dedicado à consecução de valor não apropriado pelo trabalhador. O terceiro se trata da apropriação de parte do fundo de consumo do trabalhador, reduzindo o 
fundo necessário para o trabalhador garantir sua subsistência, em favor da ampliação do fundo de acumulação do capital.

Esses mecanismos alienariam ao trabalhador as condições mínimas para garantir suas condições de reprodução. No primeiro e no segundo caso, porque a ele é imposto um ritmo de trabalho superior ao normal, fazendo com que ocorra maior dispêndio de energia que, consequentemente, intensifica seu processo de desgaste e esgotamento. No terceiro caso, porque dele é retirado o mínimo necessário para que tenha condições de garantir sua subsistência e reprodução. Na medida em que esses mecanismos se baseiam no uso intensivo e extensivo da força de trabalho, fundamenta-se um modo de produção estruturado na maior exploração do trabalhador, e não no aumento de sua capacidade produtiva, que resulta no pagamento da força de trabalho abaixo de seu valor. Isso é o que Marini chama de superexploração da força de trabalho.

A superexploração da força de trabalho seria, então, uma categoria própria à reprodução do capital nas economias dependentes, nos marcos das relações de troca no comércio internacional. Não se trata, simplesmente, de uma ampliação dos mecanismos que permitem o aumento da quantidade de bens produzidos, mas sim da intensificação dos mecanismos que, ao modificar a relação entre o tempo de trabalho necessário e tempo de trabalho excedente, permitem maior extração de mais-valor, num contexto de transferência de renda no sentido periferia-centro. A superexploração da força de trabalho seria categoria central no processo de desenvolvimento capitalista das economias periféricas e dependentes, marcadas estruturalmente pelo processo de transferência de valor, sendo, portanto, a conformação do conjunto de instrumentos que permitem a continuidade do processo de reprodução do capital nessas economias. $O$ importante a destacar é que, embora o aumento da força produtiva do trabalho seja uma forma própria de exploração do modo de produção capitalista, e os mecanismos fundados na maior exploração do trabalhador se estabeleçam por conta do desenvolvimento das forças produtivas, a compensação da renda transferida ao centro só pode se efetivar com base nos mecanismos apontados por Marini, dado o baixo desenvolvimento tecnológico dos países periféricos.

Mas não apenas a estrutura da divisão internacional do trabalho seria a razão explicativa da consolidação da superexploração da força de trabalho como categoria específica do capitalismo nas economias periféricas. Uma vez caracterizadas também pelo excedente estrutural de mão de obra, para 
Marini a ocorrência da superexploração da força de trabalho seria fortalecida pela extensão do exército industrial de reserva, categoria cuja lógica expressa, de maneira acentuada, a discrepância entre a estrutura produtiva e a força de trabalho das economias periféricas, resultando na formação de um extenso exército de trabalhadores desocupados.

Operando mediante un aumento desproporcionado de la fuerza de trabajo logrado, ya a través de la importación de mano de obra, ya de la aplicación de una tecnologia ahorrativa de mano de obra, essas economias han llevado a cabo su proceso de acumulación fundamentalmente con base en la producción de plusvalía absoluta. Para ello concurre, en parte, la falta de regulamentación de las condiciones de trabajo, y por tanto la extensión irrazonable de la jornada productiva (...); pero, también, la ruptura de la relación entre la remuneración del trabajo y su valor real, o sea, entre lo que se considera como tiempo de trabajo necesario y las necesidades de subsistencia planteadas efectivamente por el obrero (Marini, 1974, p. 115).

Ainda que a consolidação da condição dependente - fundamentada na arquitetura da divisão internacional do trabalho, na transferência de valor periferia-centro e na utilização dos mecanismos de superexploração da força de trabalho - fosse aspecto da estrutura econômica, política e social das nações latino-americanas, não foi obstaculizado o processo de industrialização da região. A compreensão da transição do eixo de acumulação dos países latino-americanos para a indústria, uma vez tendo como base a restrição externa e o processo de substituição de importações, requer atenção, não propriamente pelo desenvolvimento da indústria em si, mas das bases sobre a qual ela se consolidou, sendo esses elementos centrais para a compreensão da forma de articulação da região ao movimento de expansão do capital internacional.

A indústria se instala nos países periféricos voltada ao atendimento de uma estrutura de demanda já existente, consumidora de bens suntuários anteriormente supridos por importações. Uma indústria, portanto, que se desenvolve sem um mercado interno suficiente para lhe dar sustentação, impulsionada pelas crises do mercado internacional, com uma frágil estrutura e pouca capacidade de expansão. Diante desses entraves, a indústria periférica se ergueu sobre bases que necessitavam de uma estrutura de distribuição de renda desigual, possuindo mecanismos eficientes para rebaixar os salários dos trabalhadores em favor dos ganhos capitalistas. Isso porque, do ponto de vista da produção, se aproveitava do excedente de força de trabalho criado pelo setor exportador para criar uma permanente pressão para a redução dos salários. Da perspectiva da realização, atendia a 
uma demanda composta por classes de elevada renda, para quem oferecia produtos sobre os quais possuíam o monopólio da produção. A conjugação de uma produção monopolista e de baixos custos de produção e salários resultava na desigual distribuição de renda, que garantia os elevados lucros e a sobrevivência da indústria. E, mais do que isso, erigia um novo eixo de acumulação que, assim como o anterior, era fundado na ampliação da superexploração da força de trabalho.

Desse modo, a condição dependente e a superexploração da força de trabalho se conformam como características estruturais dessas economias, que tendem a se perpetuar independente do eixo de acumulação. De acordo com Marini (2000), se, num primeiro momento a superexploração se dava pela separação entre produção e circulação em função das imposições do comércio internacional, a partir do momento em que esses países se industrializam ela passa a ser efeito da separação entre a esfera alta - por onde circulam os bens suntuários - e a esfera baixa de circulação - a dos bens-salário - no interior de cada economia. Assim, o processo de industrialização da periferia em si não engendra fatores que modificam as condições de salários dos trabalhadores, seja porque os bens manufaturados, ao não comporem de forma determinante a cesta de consumo dos trabalhadores, não influenciam diretamente no valor da força de trabalho, seja porque a redução dos salários resultante da superexploração não implicará problemas de realização da produção, dado que são outras as camadas que compõem a demanda pelos bens manufaturados.

Por outro lado, mesmo que a industrialização periférica ocorra às expensas da absorção de tecnologias obsoletas, ocorre certo grau de ampliação da produtividade do trabalho, criando condições para a ampliação da produção do mais-valor relativo. Essas tecnologias, poupadoras de mão de obra, acabam por criar uma massa de trabalhadores desocupados ou ocupados em formas de trabalho não produtivas. Assim, o avanço da acumulação de capital ocorre fundado na redução relativa do nível de emprego, ao passo que o aumento do exército de reserva atua na compressão dos salários, ampliando o número de trabalhadores submetidos à situação de rebaixamento de seus níveis de remuneração (Marini, 2012). Observa que a ampliação do mais-valor relativo não suprime aqueles que resultam em um mais-valor absoluto maior, mas, ao contrário, os intensifica, passando-se a um estágio no qual ambos agem de forma conjunta na ampliação da exploração da força de trabalho e na valorização do capital. Nesse sentido, 
agudizam as contradições do modo de produção capitalista, na medida em que os mecanismos que condicionam a superexploração da força de trabalho contribuem para que a mesma se efetive a partir de uma estrutura que reforça os mecanismos da superexploração. ${ }^{4}$

Segundo Marini (2000) o que ocorre a partir da industrialização dos países periféricos é uma nova hierarquização da economia capitalista mundial baseada na redefinição da divisão internacional do trabalho. Nessa nova divisão, reservam-se para os centros imperialistas as etapas mais avançadas da produção industrial, com monopólio das tecnologias correspondentes, e aos países dependentes, as etapas inferiores da produção industrial. Consequentemente, esses países tornam-se capazes de incorporar não apenas os produtos das indústrias pesadas dos países centrais, mas também as tecnologias já obsoletas, antes de se completar o prazo de reposição do capital fixo anteriormente aplicado. Ademais, servem de mercado para o capital altamente concentrado das corporações imperialistas.

No entanto, se por um lado o processo de industrialização dos países dependentes contribuiu para o equacionamento dos possíveis entraves à acumulação de capital nos países centrais, de outro lado a absorção de progresso técnico em condições de superexploração da força de trabalho cria obstáculos ao ciclo do capital na economia dependente. Ao limitar a capacidade de consumo da classe trabalhadora, a economia dependente acarreta inevitável restrição do mercado interno, criando entraves ao consumo de parte da produção. Razão pela qual esses limites, ao refletirem sobre a capacidade de geração de mais-valor, irão impor aos países periféricos a necessidade de expandir seu mercado para o exterior. Será a partir da reorganização do modelo da economia exportadora que se inicia, nas economias dependentes, o fenômeno do subimperialismo.

\subsection{Subimperialismo}

Apesar dos limites impostos por um capitalismo que se consolida com a superexploração da força de trabalho, não foram criados entraves ao processo de industrialização das economias dependentes, que se estabeleceu

4 É a essa possibilidade de que se efetivem processos de desenvolvimento das forças produtivas, sem que os problemas estruturais das economias dependentes sejam superados, que Frank (1980) chamou de "desenvolvimento do subdesenvolvimento". 
a partir dos interesses do capital imperialista altamente concentrado nos países centrais. Nesse sentido pode-se dizer que a industrialização dos países dependentes se firmou como aspecto de uma nova etapa do avanço do imperialismo em nível internacional, reconfigurando a hierarquia na divisão internacional do trabalho, estruturalmente dependente da dinâmica dos países centrais e baseada numa lógica convergente com a marginalização das condições da força de trabalho e as restrições ao mercado interno. São esses, em síntese, os elementos dos quais partem a formulação da categoria subimperialismo ${ }^{5}$.

O entendimento da categoria, no entanto, requer a análise de alguns aspectos estratégicos da política externa brasileira a partir da década de 1950, que se apresentam como fundamentos históricos de sua formulação, por se basearem numa nova etapa do desenvolvimento capitalista no país. Cabe ressaltar, no entanto, que apesar de lançar mão do caso brasileiro para o delineamento da categoria, uma vez que o país, a partir da década de 1950, passou a ser expressão acentuada e plena dessa tendência - "[o] caso brasileiro é, particularmente nessa questão, paradigmático" (Marini, 2012a, p. 131) -, Marini indica que não se trata de um fenômeno especificamente brasileiro, nem tampouco corresponde a uma anomalia do capitalismo dependente.

Com a implantação do parque industrial, o aumento das exportações passou a ser visto como mecanismo essencial para a continuidade do processo de desenvolvimento, por meio do modelo de substituição de exportações. Tal modelo concedeu ao comércio exterior o papel de promover maior arrecadação das exportações por meio de uma política de promoção dos manufaturados brasileiros no exterior, via flexibilização do câmbio e maior inserção, na pauta de exportação brasileira, de produtos de maior conteúdo tecnológico. Esse modelo converteu-se no eixo fundamental do vínculo do comércio exterior, do ponto de vista técnico - a partir de reformulações nas esferas monetária e cambial, e na legislação do mercado de capitais e tributária - e do ponto de vista diplomático - a partir da recuperação de uma política universalista de comércio exterior, em especial com

5 Santos (1973) e Bambirra (2013) também tiveram contribuições para a formulação da categoria subimperialismo. De modo geral, a análise dos autores está centrada na compreensão das contradições geradas entre o país subimperialista e os que seriam objeto de sua dominação, mais do que nos antagonismos entre o centro imperialista e o centro subimperialista, os quais, ao contrário de resolver os problemas de cunho econômico, seria fator que ampliaria as contradições do capitalismo dependente. 
a aproximação aos países periféricos. Tal política passou a ser vista como fundamental em decorrência do acúmulo de déficits e atrasados comerciais resultantes da promoção de instrumentos de total liberdade ao mercado de câmbio e às operações comerciais e financeiras com o exterior, prevalecentes durante a primeira metade da década de 1950 (Silva, 2003).

Ademais, a expansão da indústria no Brasil mantém relação direta com a própria expansão dos investimentos de capitais estadunidenses na região. $O$ movimento de investimento dos Estados Unidos da América (EUA) em direção aos países latino-americanos encontrava respaldo, segundo Marini (2012), em três principais razões: na necessidade de ampliar a valorização do capital em nível mundial, aproveitando-se de condições específicas em determinadas regiões; o crescimento da indústria de bens de capital, que criava a necessidade de se formar novos mercados para ela, e que pressupunha a existência de um setor industrial em outros países; e a necessidade de diversificar a produção como forma de evitar a acumulação de capital em setores altamente concentrados. Fato é que, aproveitando-se da expansão dos investimentos dos EUA, a industrialização do Brasil avançou a ponto que o país conseguiu ser uma das primeiras economias subdesenvolvidas a realizar a transição de um aparato industrial baseado no protecionismo concedido às atividades voltadas para o atendimento do mercado interno para uma fase de abertura crescente para o exterior, com a promoção de exportações não tradicionais e progressiva liberalização.

Porém, essa nova estratégia requeria um reenquadramento das relações políticas do Brasil com outras regiões. Entre a década de 1960 e o final dos anos de 1980, o Brasil teve, basicamente, duas políticas externas. A primeira, instituída por Jânio Quadros, ficou conhecida como política externa independente e possibilitou que o Brasil pudesse expandir mercados para seus produtos e fortalecer-se econômica e politicamente frente a outros países dependentes. Com a chegada dos militares ao poder, passou-se a defender uma política de interdependência com os EUA - a política de barganha legal - a qual envolvia garantir ao Brasil o controle estratégico da segurança da América do Sul, ratificando-o como principal satélite americano na região (Mota Filho, 2017). Estavam construídas as bases históricas do subimperialismo.

Definimos, em outra oportunidade, o subimperialismo como a forma que assume a economia dependente ao chegar à etapa dos monopólios e do capital financeiro. O subimperialismo implica dois componentes básicos: por um lado, uma compo- 
sição orgânica média na escala mundial dos aparatos produtivos nacionais e, por outro lado, o exercício de uma política expansionista relativamente autônoma, que não apenas é acompanhada de uma maior integração ao sistema produtivo imperialista, senão que se mantém no marco da hegemonia exercida pelo imperialismo à escala internacional (Marini, 2012, p. 33).

O fenômeno descrito por Marini parte da relação entre a formação do capital monopolista nos países centrais e o processo de constituição do capitalismo na periferia. Desde o estabelecimento das relações entre as diferentes regiões no âmbito do comércio internacional, e de maneira mais proeminente quando da aceleração do processo de concentração e centralização de capital, o capital estrangeiro assume na América Latina a função de se apropriar do mais-valor criado dentro de cada economia nacional, mediante empréstimos públicos e privados, financiamentos, aplicações em ações e investimentos diretos, reforçando a dependência que das economias latino-americanas em relação aos recursos gerados no setor exportador, sendo este o principal dinamizador das economias internas. Tal estrutura de relação se reproduz quando da efetivação do processo de industrialização dos países periféricos, que se consolida a partir da integração imperialista da economia mundial. Do ponto de vista interno, o processo de industrialização via substituição de importações representou uma relativa superação das restrições impostas pelo setor externo, resultando na diversificação produtiva, na dinamização do setor produtor de bens de consumo não duráveis, mas também no enquadramento das mais avançadas economias latino-americanas à nova lógica da economia internacional, marcada pelo surgimento de novas regiões produtoras e pela reorganização da divisão internacional do trabalho. A organização do setor produtor de bens manufaturados na América Latina, beneficiado pelas restrições do setor exportador e pela canalização do excedente produtivo desse setor para investimentos na indústria via sistema bancário, significou um pacto mútuo entre a burguesia agrário-mercantil e a burguesia industrial ascendente, cuja relação foi moldada através do estabelecimento de um Estado de compromisso.

Fato é que as necessidades impostas ao avanço do capitalismo nos países centrais fizeram com que, mediante o processo de industrialização da América Latina, se reconfigurassem as relações de dependência. Nessa nova arquitetura da divisão internacional do trabalho, são transferidas aos países periféricos etapas inferiores do processo de produção, reservando as etapas mais avançadas e o controle da tecnologia e inovação corres- 
pondente aos centros imperialistas, reforçando, a cada avanço da indústria latino-americana, sua dependência econômica e tecnológica frente aos centros imperialistas.

Mas esse não seria o único efeito possível do novo esquema de divisão internacional do trabalho. Considerando particularmente as relações econômicas estabelecidas na região latino-americana, poderia-se constituir entre essas nações níveis ou hierarquias segundo os ramos de produção que se desenvolveram, ficando concentrado em determinados países o monopólio da produção de bens industriais, enquanto a outros seria relegado o papel de mercado consumidor para esses produtos. Internalizavam-se, assim, nas relações econômicas intra-regionais, as mesmas estruturas produtivas e do comércio internacional, operando na própria periferia do sistema as relações de dependência, subordinação e exploração vigentes na relação centro-periferia. A reafirmação do imperialismo, assim, se traduz não apenas em nova integração da América Latina, mas também na reprodução interna de seus elementos nos processos de integração regional. Esses novos arranjos resultarão, segundo Marini, na formação de centros subimperialistas, associados à metrópole, voltados à exploração dos povos vizinhos.

Como quer que seja, a expansão e a aceleração tanto da circulação do capital produtivo como da circulação do capital dinheiro foram configurando uma nova economia mundial capitalista, que repousa sobre um esquema de divisão internacional do trabalho distinto daquele vigente antes da crise mundial (...). Já se foi o tempo do modelo simples centro-periferia, caracterizado pelo intercâmbio de manufaturas por alimentos e matérias-primas. Encontramo-nos diante de uma realidade econômica na qual a indústria assume um papel cada vez mais decisivo. Isto é certo ainda que o capital industrial se amplie e se fortaleça em áreas extrativas e agrícolas; mais ainda, quando consideramos a extensão e a diversificação em escal a mundial da indústria manufatureira. O resultado tem sido um reescalonamento, uma hierarquização dos países capitalistas em forma piramidal e, por conseguinte, o surgimento de centros medianos de acumulaçãoque são também potências capitalistas medianas -, o que nos têm levado a falar da emergência de um subimperialismo (Marini, 2012, p. 43).

Ocorria então que, no interior das economias periféricas, se constituiriam centros medianos de acumulação, como resultado do processo de diversificação e concentração da indústria manufatureira em escala mundial, o que seria possível a partir da articulação de algumas nações ao movimento mais geral de expansão do imperialismo. A articulação econômica e política de países periféricos aos países centrais, a partir do estreitamento entre o capital externo e a burguesia nacional e da internacionalização da indústria manufatureira a partir de sua instalação nesses países, permitiu a emergência de centros produtivos mais dinâmicos na América Latina 
- exatamente aqueles denominados por Marini como centros medianos de acumulação.

No entanto, a tendência é que tais setores produtivos recaiam num duplo processo: de um lado, reproduzindo os mesmos padrões observados nas atividades primário-exportadoras, com prevalência da elevada superexploração da força de trabalho e extensão do exército industrial de reserva, já que baseadas em tecnologias mais produtivas e, portanto, fundadas numa maior composição orgânica do capital, promovendo marginalização e redução da capacidade de consumo da classe trabalhadora. De outro lado, a concentração dessa produção industrial em bens de consumo suntuários, voltados exclusivamente para as classes de rendas mais elevadas. Assim, tal indústria se desenvolve numa estrutura restritiva para realização da produção, seja pelo direcionamento para as classes de altas rendas, seja pelas restrições impostas ao crescimento do mercado consumidor. Por tais razões, a abertura ao mercado exterior para a exportação de bens manufaturados se apresenta como solução para o problema de realização da produção, utilizando-se estratégias de domínio de mercado. De acordo com Amaral (2012), o subimperialismo seria uma forma de compensar, nas relações entre os países dependentes, as perdas sofridas nas relações estabelecidas em nível mundial, ou um imperialismo dentro do campo dependente, exercido por países cuja integração à lógica imperialista mundial se encontra num estágio avançado, mas ainda dentro dos marcos da dependência. Nesse sentido, seria uma espécie de imperialismo dependente. ${ }^{6}$

Mas a penetração do capital estrangeiro nas economias latino-americanas não ocorre sem contradições, na medida em que os processos de 6 A tese do imperialismo de Lênin prescinde de aspectos importantes daquela referente ao desenvolvimento desigual e combinado de Trotsky, segundo a qual a ascensão do capitalismo, em nível internacional, proporcionaria o desenvolvimento de regiões periféricas, ainda que não nos mesmos marcos que nos países centrais, podendo combinar setores produtivos avançados com setores tradicionais. Ainda assim, nesse caso, poderia ocorrer que, em alguns setores, o nível de avanço técnico adotado fosse superior àquele verificado nos países centrais. Essa leitura, em certo sentido, poderia ser contraposta à interpretação da teoria marxista da dependência, na medida em que esta percebe a impossibilidade do desenvolvimento capitalista autônomo na periferia. Essa é a razão pela qual as teses formuladas pela teoria se apresentam não como alternativas à tese do imperialismo, senão como complementares, na medida em que permitem a observação de fatos concretos - o avanço do capitalismo na periferia no pós-Segunda Guerra e seus resultados - que, na época de Lênin, poderiam ser tomados apenas como possibilidades do avanço do sistema capitalista em nível mundial. $O$ que se verifica, na prática, é que o avanço tecnológico na periferia ocorre em bases estreitas e sempre a partir de tecnologias já obsoletas nos países centrais. E mesmo no caso onde há aplicação de tecnologias avançadas, esse avanço ocorre a partir da dominância do capital externo sobre os setores produtivos internos. 
cooperação e integração do capital imperialistas nas economias nacionais resultam em acirramento do conflito de classes - seja entre grupos industriais e latifundiários exportadores, entre indústria e agricultura para o mercado interno, ou entre os grandes proprietários rurais e o campesinato - e dos interesses dos capitais estrangeiro e nacional. Por isso, é a partir da cooperação antagônica ${ }^{7}$ que se firma a integração entre o capital imperialistas e os centros médios de acumulação, e tal é a relação histórica estabelecida entre o capital estadunidense e a economia brasileira, em especial a partir do Plano de Metas, quando ganha impulso o processo de consolidação da indústria no Brasil. No entanto, o esgotamento da expansão industrial no Brasil, no início dos anos de 1960, demarcada pela diminuição da renda interna, pela queda do preço e do volume das exportações, pela grande exportação de lucros e pela crise cambial e aceleração da inflação, criou a necessidade de um novo arranjo geopolítico no processo de integração imperialistas, o que seria levado a cabo com o golpe militar de 1964.

É após o golpe militar que se efetiva a política externa brasileira fundada na interdependência continental. Essa nova política externa era fundada no reconhecimento geopolítico da inviabilidade da associação política do Brasil aos Estados Unidos, a partir da aceitação, por parte destes, do quase monopólio da dominação brasileira na região latino-americana. Tratava-se, tão somente, da vinculação do Brasil à lógica imperialista estadunidense, garantindo o monopólio da dominação na América do Sul,

[a partir da evolução] da burguesia brasileira rumo à aceitação consciente de sua integração ao imperialismo estadunidense, evolução esta que resulta da própria lógica da dinâmica econômica e politica do Brasil e que poderia ter graves consequências para a América Latina (Marini, 2012a, p. 121).

A nova política externa brasileira não se tratava de uma aceitação passiva das decisões estadunidenses, mas, antes disso, de uma colaboração ativa com a expansão imperialista, assumindo posição-chave nessa expansão. Essa integração, por outro lado, reativava a expansão econômica nacional,

7 De acordo com Souza (2017), a categoria cooperação antagônica "foi cunhada pelo marxista alemão August Thalheimer com a qual buscou demonstrar que a integração imperialista desenvolve as contradições intrínsecas ao capital e que, ainda que a necessidade de auto defesa das economias imperialistas na contemporaneidade não leve a rupturas que culminem em guerras como nos períodos anteriores, outras formas de conflito emergem dessa relação.". Segundo a autora, a categoria é usada por Marini para explicitar o pacto contraditório entre as burguesias nacionais no Brasil e as imperialistas, a qual expõe as contradições que, de modo geral, apontariam para a própria negação de tal integração. 
ao permitir o processo de renovação tecnológica da indústria, de interesse nacional - pela modernização e avanço do seu parque industrial - e externo - pela possibilidade de aplicação de excedentes ociosos que permitam, na América Latina, a absorção de tecnologias já obsoletas nos países centrais. Por seu turno, a nova fase da indústria no Brasil e sua expansão colocariam os interesses nacionais em conflito com os interesses estadunidenses, ao engendrar, no plano político interno, a necessidade de imposição dos interesses nacionais nas decisões econômicas.

No entanto, por se tratar de um país com forte crescimento demográfico, a implementação da industrialização com tecnologia poupadora de mão de obra criaria não apenas gargalos para a absorção da massa de trabalhadores, mas também para a expansão do mercado interno em nível capaz de absorver o aumento da produtividade. Não restaria ao Brasil, assim, outra solução que não a tentativa de expansão para o mercado externo, que garantisse uma reserva externa de mercado para sua produção. A expansão imperialista do Brasil na América Latina, que segundo Marini corresponde ao subimperialismo, seria então a solução que, de um lado, consolidaria a nova fase de expansão industrial do Brasil, e, de outro, conformaria o processo de expansão imperialista, especificamente dos EUA, sobre e América Latina.

\section{3 À guisa de conclusão: o movimento político na obra de Marini}

Apesar de a interpretação acerca do desenvolvimento capitalista na periferia ser foco de sua versão da TMD, as preocupações de Marini estavam para além do entendimento da conformação econômica e social em decorrência da situação de dependência. Tendo na teoria marxista do valor o aporte teórico e categorial sobre o qual desenvolveu sua análise, sua preocupação se direcionava para a compreensão das contradições do sistema capitalista na periferia, dos seus desdobramentos e das possibilidades abertas à resolução de seus gargalos. Mais especificamente, como operam as leis de tendências particulares da dependência - transferência de valor como intercâmbio desigual, a superexploração da força de trabalho e a 
cisão no ciclo do capital ${ }^{8}$ - na estrutura das relações econômicas, sociais e políticas dos países latino-americanos.

Entendendo que os entraves ao desenvolvimento econômico e social decorrentes da situação dependente só poderiam ser vencidos com a própria superação do sistema capitalista, ganharam importante destaque na obra de Marini os arranjos políticos e os movimentos de contestação da ordem vigente, em especial aqueles que se formam após o golpe militar de 1964, pois da organização desses movimentos poderiam emergir a crítica ao sistema capitalista e a organização social em novas bases. Em outras palavras, a tese e as categorias elaboradas pelo autor só têm fundamento se compreendidas nos marcos do capitalismo periférico, no projeto econômico interno e externo, e nos movimentos políticos que tinham como objetivo a contraposição ao arranjo político que se instaura a partir da década de 1960. E mais do que isso, como instrumentos teórico-políticos para o entendimento da realidade latino-americana, os quais permitissem dar novos contornos às possibilidades de efetivação da revolução brasileira.

De acordo com Marini, o capitalismo latino-americano, para além de reproduzir as leis gerais que regem o modo de produção capitalista, as acentuaria até seu limite, estabelecendo a superexploração da força de trabalho como aspecto estrutural, e a concentração da riqueza e pauperização absoluta da grande maioria da população como suas implicações imediatas. Tais seriam os motivos que colocariam a exigência da formulação e da prática de uma política revolucionária de luta pelo socialismo. De modo geral, a luta pelo socialismo ganharia contornos, na América Latina, a partir dos efeitos da forma própria de integração imperialista da região, que criariam tendências para a eclosão do movimento revolucionário latino-americano.

En lo que se refiere a la revolución latinoamericana, se debe hacer notar que (...) la integración imperialista de los sistemas de producción en América Latina está forjando su propia negación. Ella se ha manifestado ya en el triunfo del socialismo en Cuba y sigue desarrollándose a través de las luchas de clase que tienen lugar en toda la región y que alcanza su forma más alta com la actividad guerrillera llevada a cabo en Venezuela, Guatemala, Colombia y otros países. El avance incontenible de las masas explotadas se orienta inevitablemente hacia la sustitución del actual sistema de producción por otro que permita la plena expansión de las fuerzas productivas y que redunde en una elevación efectiva de los niveles de trabajo y de consumo: es decir, el sistema socialista (Marini, 1974, p. 10).

8 As leis de tendência específicas eram aspectos que definiam a essência do capitalismo dependente na obra de Marini e, por isso, permitiam o estabelecimento de uma espécie de teoria intermediária que, fundada na obra de Marx, conduzisse à compreensão do caráter subdesenvolvido e dependente da economia latino-americana e sua legalidade específica (Luce, 2018). 
O capitalismo na periferia, então, assumiria uma dinâmica na qual exerce com vigor o sentido dialético das relações sociais, com a agudização das leis gerais do capitalismo e suas manifestações em leis e desdobramentos históricos específicos - as leis do capitalismo dependente - observados nos níveis de desigualdade existentes nos países dependentes, na concentração de populações vivendo em favelas em várias partes do mundo, mas também pelo controle monopolista de determinadas tecnologias pelas economias capitalistas (Luce, 2018). A exacerbação desses fenômenos e sua compreensão como elementos estruturais das economias periféricas colocariam como fundamental a organização do movimento revolucionário latino-americano, os quais seriam animados por dois principais aspectos: o estabelecimento de uma relação mais efetiva entre as classes exploradas e suas vanguardas políticas; e o estabelecimento de relações entre essas classes no marco mais amplo do contexto internacional (Marini, 1974).

A partir disso, se percebe o estabelecimento entre os vínculos teóricos do capitalismo dependente - formulados com base nas leis do capitalismo dependente, quais sejam, a superexploração da força de trabalho, o divórcio entre as fases do ciclo do capital, a monopolização da indústria, a integração dos sistemas de produção e o subimperialismo -, sua importância para a compreensão da realidade latino-americana - o entendimento da estrutura econômica, política e social decorrentes da condição periférica e dependente - e os possíveis caminhos para a superação dos entraves ao desenvolvimento socioeconômico - o movimento revolucionário latino-americano. Esses são os elementos que fariam da TMD, como parte da tradição do marxismo, uma teoria militante, voltada não somente à interpretação do capitalismo periférico, mas também no sentido da organização política da classe trabalhadora e sua atuação para a transformação da sociedade.

Ao analisar o caso brasileiro, Marini aponta que o compromisso político firmado em 1937 entre o governo e as distintas classes - de um lado, os benefícios à classe trabalhadora através do avanço na legislação social, à burguesia através dos mecanismos para o avanço da industrialização frente à crise externa, e os benefícios à oligarquia rural diante das políticas de defesa dos produtos primários - se estendeu até meados da década de 1950. A ruptura desse compromisso começa a se desfazer quando a crise do setor externo se difunde para o conjunto do sistema, implicando dificuldades tanto para a geração de divisas necessárias ao avanço no processo de 
industrialização, quanto para a capacidade de abastecimento das cidades. Para a classe trabalhadora, a gradual modernização tecnológica, frente à ampliação da mão de obra liberada pela agricultura, criava dificuldades cada vez maiores para a absorção dos trabalhadores, gerando pressões por melhores condições de salários e trabalho. É assim que o compromisso político entre as classes começa a se desfazer, abrindo espaço para tentativas de sua revisão, como ocorreu no segundo governo Vargas, assim como nos governos de Jânio Quadros e João Goulart. Mas é apenas com a consolidação da investida imperialista no Brasil, efetivada com o golpe de 1964, que tal compromisso é refeito, fundamentado, como discutido na seção anterior, com base na noção de interdependência continental.

A ditadura militar ensejou novos aspectos para a compreensão da dependência e do subimperialismo. Ao desenvolvimento industrial articulado à estratégia das multinacionais em nível mundial e à associação aos EUA para o enquadramento do Brasil como centro médio de acumulação, uniu-se a profunda política de desvalorização do salário mínimo e a política econômica recessiva, que tiveram como consequência direta a falência de pequenas e médias empresas e o aumento do desemprego. A projeção da indústria brasileira sobre a economia de outros países dependentes, frente a uma ampla capacidade ociosa e à demanda fortemente comprimida, e os mecanismos da superexploração da força de trabalho se apresentaram como alternativa econômica para a resolução dos problemas referentes à continuidade do processo de desenvolvimento (Mota Filho, 2017).

Nesse sentido, Marini (2012) aponta que o subimperialismo brasileiro não era apenas a expressão de um fenômeno econômico, mas em ampla medida resultado da luta de classes no país e do projeto político definido pela equipe tecnocrática-militar que assume o poder em 1964. Era uma reação não apenas aos movimentos de massa em ascensão na América Latina e à nova dinâmica da integração imperialista, no intuito de atrair para o Brasil capitais internacionais, mas também voltada à tentativa de assegurar campos de investimento no exterior através das operações com empresas estatais, créditos intragovernamentais e garantias de operações privadas em países da América Latina e África. Era a ação da geopolítica na América Latina, que aqui se estabelece na esteira da influência estadunidense sobre um conjunto de países a partir de acordos bilaterais de cooperação técnica e programas de formação de quadros, a partir do enfoque militar da política. 
Na América Latina, é a doutrina da contra-insurgência que dará a tônica da política internacional dos Estados Unidos na região e nos seus respectivos projetos de fortalecimento nacionais. Isso se deveu por uma dupla determinação: a atuação dos EUA no apoio à substituição de regimes democráticos liberais por ditaduras militares na maioria dos países da região, e a formulação do projeto de potência dos militares, voltado para a transformação dos interesses da burguesia à categoria de interesses nacionais. A concretização do projeto político-econômico dos militares se concretizaria a partir da promoção do interesse nacional no plano internacional, especificamente na região latino-americana (Marini, 1985).

Por tais razões, o subimperialismo não seria apenas um elemento que aflui da perspectiva das relações econômicas, mas também da perspectiva das relações políticas. É, nesse sentido, ação orientada do Estado no intuito de implementar o projeto da burguesia brasileira, projeto de classe e com interesses demarcados e específicos, coadunado com o movimento do capital internacional e, em consequência, diametralmente oposto aos interesses da classe trabalhadora no Brasil. A ditatura militar no Brasil deve ser compreendida enquanto instrumento e resultado do desenvolvimento do tipo de capitalismo de Estado subimperialista, representado pela garantia da acumulação de capital com base na superexploração da força de trabalho, mas também como expressão da hegemonia conquistada pelos monopólios industriais e pelo capital financeiro nacional e internacional (Marini, 1971).

Assim, o projeto subimperialista deveria ser enfrentado nos marcos do conflito de classes, porque concretamente representava o aprofundamento do capitalismo dependente, de suas leis de tendência, e dos impactos sobre as condições da classe trabalhadora e da autonomia das relações econômicas, políticas e sociais. Por isso, esse novo arranjo veio acompanhado de um conjunto de conflitos sociais - para os quais jogaram importante papel os diversos partidos políticos da esquerda e os movimentos sociais que se destacaram no período.

Se, até o golpe militar, o Partido Comunista do Brasil (PCB) havia exercido importante papel como articulador dos grupos de esquerda, a construção de alternativas independentes passa a ganhar força quando se torna claro que a influência de grupos burgueses sobre o partido conduzia a orientação das massas como mecanismo de apoio à sua política de defesa do reformismo. Assim, frente às transformações na conformação de classes resultante da inflexão no processo de industrialização a partir da década 
de 1950, quando o capital passa gradualmente a migrar para a indústria de bens intermediários, de capital e de consumo durável, os quais resultam, inevitavelmente, na agudização das contradições entre as distintas classes e no acirramento das disputas por frações do excedente econômico, o PCB reforça o conteúdo anti-imperialista e antifeudal de sua luta, na defesa de um caminho pacífico como via, as reformas como instrumento, e a frente única entre a burguesia e o proletariado como garantia (Marini, 2012a).

Como não se tratava de um país enfrentando tropas de ocupação imperialista que justificassem uma frente popular com setores da burguesia, e como a superexploração da força de trabalho era mecanismo praticado pelo grande capital para fins de reprodução do capital e garantia de seus interesses, Marini não via razões para crer que a oposição efetiva ao regime militar pudesse se construir pela via da revolução democrático-burguesa. No mesmo sentido, também concebia críticas ao que chamou de "militarismo de esquerda" e às teses do foquismo, praticado pelas linhas de diferentes organizações, que defendiam a luta armada na resistência à ditadura. Para o sociólogo, as disputas políticas internas não apontavam que a luta revolucionária se encaminhasse tanto para a perspectiva de guerra popular prolongada, quanto pela luta armada (Luce, 2018).

Com a incapacidade de a política nacionalista e reformista impedir o avanço do imperialismo nacional, surge a esquerda revolucionária como forma de dar nova condução à luta política da classe trabalhadora, a qual ganhará forma, ao longo da década de 1960, através das Ligas Camponesas e da Política Operária (Polop). Marini dá especial destaque, entre os grupos de esquerda que surgiram ao longo da década de 1960, ao papel desempenhado pela Polop. Segundo o autor,

a Polop analisou melhor que qualquer outra organização os principais aspectos
da concepção que fundamentava a prática política das diferentes forças e abriu
uma tradição teórica que marca profundamente a atual esquerda revolucionária
do Brasil, inclusive em seus desvios. Os elementos centrais a serem considerados
seria basicamente os seguintes: a) a questão do caráter da revolução brasileira;
b) a determinação das classes revolucionárias e seus aliados; c) a forma que as-
sumirá o processo revolucionário nas condições concretas do país (Marini, 2012a,
p. 218).

Ao centrar sua crítica à concepção reformista, a Polop não apenas percebeu que as condições de atraso político dariam ao proletariado um caráter de subordinação à classe política burguesa - fator que engrandecia a necessidade de formação de quadros políticos - mas também defendia pela primeira vez o caráter socialista da revolução brasileira. 
A experiência da Polop trazia elementos caros a Marini à constituição de um partido revolucionário, que ele considerava fundamental para a formação política, a ampliação do nível de consciência política das massas e para a construção efetiva de uma alternativa de poder ao enfrentamento do capital. E, embora tenha incorrido em erros estratégicos - como a aceitação de que o processo revolucionário deveria privilegiar a cidade em relação ao campo, e a concentração da ação em torno da classe operária, então politicamente dominada pelo $\mathrm{PCB}$ - que resultaram na contribuição em escala muito reduzida para a formação da frente revolucionária, a Polop contribuiu de forma inequívoca para a reorganização de grupos de esquerda cujo centro da análise política se distanciava de uma possível associação entre burguesia e classe trabalhadora.

A vanguarda representada pela Polop ganhou contornos na organização de outros grupos de esquerda a partir de 1968, que representaram o nascimento de um movimento de massas qualitativamente distinto, organizado fora da perspectiva reformista e próximo à interpretação da necessidade de efetivação do processo revolucionário. É a partir da Polop que surgem então três grupos que ganham relevância na formação política da esquerda: a) Partido Operário Comunista (POC), que reivindicava a linha da velha organização; b) a Vanguarda Popular Revolucionária (VPR), uma das organizações político-militares mais influentes a partir de então; e c) o Comando de Libertação Nacional (COLINA). Da desintegração do PCB, surgiria ainda a Ação Libertadora Nacional (ALN) e o Partido Comunista Brasileiro Revolucionário (PCBR), orientado por uma linha revolucionária de trabalho de massas. Além destes, as dissidências comunistas, que agrupavam, no âmbito estadual, as bases juvenis do antigo partido.

Apesar das mais distintas divergências entre esses diferentes grupos, o fundamental nesta análise de Marini é a apreensão da importância que eles cumpriram para a formação da esquerda no Brasil, e o papel importante que exerceram na contraposição aos movimentos políticos e econômicos efetivados desde a década de 1960, com a formatação de uma arquitetura institucional entre burguesia interna e capital imperialista para a transformação do Brasil num centro de irradiação do capital em nível internacional a partir da defesa imanente dos interesses externos. Esses grupos cumpriram papel fundamental na luta de classe, na defesa dos interesses da classe trabalhadora e na cisão dos interesses com a classe burguesa. Desse modo, eles conduziram o debate teórico e político para aquilo que, segundo Ma- 
rini, era fundamental no processo de transformação da economia e da sociedade periférica: a necessidade de contestação e superação do sistema capitalista como forma única de equacionar os problemas estruturais de qualquer sociedade fundada nas bases do capitalista, mais especificamente, nas bases do capitalismo periférico e dependente, fator que se instaurava como grande desafio da esquerda revolucionária na condução da luta política na América Latina. Contestação esta para a qual, do ponto de vista da formulação teórica a partir da análise das condições concretas, sustentadas no método histórico-dialético, contribuíram de maneira fundamental as categorias superexploração da força de trabalho e subimperialismo.

\section{Referências}

AMARAL, M. S. Teorias do imperialismo e da dependência: a atualização necessária ante a financeirização do capitalismo. Tese (doutorado) - Faculdade de Economia, Administração e Contabilidade da Universidade de São Paulo (FEA-USP), São Paulo, 2012.

BAMBIRRA, V. Capitalismo dependente latino-americano. Florianópolis: Insular, 2013.

BAMBIRRA, V. La teoria de la dependencia: una anticrítica. Material de formación política de la "Cátedra Che Guevara - Colectivo AMAUTA". 1978. Disponível em: <http://www. amauta.lahaine.org>. Acesso em: outubro de 2019.

BIELSCHOWSKY, R. Cinquenta anos de pensamento na CEPAL. Rio de Janeiro; São Paulo: Record, 2000.

CARDOSO, F. H.; FALETTO, E. Dependência e desenvolvimento na América Latina - ensaio de interpretação teórica. Rio de Janeiro: Civilização Brasileira, 2004.

FONTES, V. O Brasil e o capital-imperialismo: teoria e história. Rio de Janeiro: EPSJV/Editora UFRJ, 2010.

FRANK, A. G. América Latina: subdesarrollo o revolución. México: Ediciones Era, 1980. (Coleção El Hombre e su Tiempo).

LUCE, M. S. Teoria marxista da dependência: problemas e categorias. Uma visão histórica. São Paulo: Expressão Popular, 2018.

MARINI, R. M. A acumulação capitalista mundial e o subimperialismo. Trad. Maíra Machado Bichir e Fábio Pádua dos Santos. Outubro, n. 20, pp. 27-70, 1 semestre 2012.

MARINI, R. M. Dialética da dependência. In: SADER, E. (Org.). Dialética da dependência: uma antologia da obra de Ruy Mauro Marini. Petrópolis: Vozes/CLACSO/Laboratório de Políticas Públicas, 2000. pp. 105-165. (Coleção A Outra Margem).

MARINI, R. M. Geopolitica latino-americana. 1985. Disponível em: <http://www.marini-escritos.unam.mx/>. Acesso em: dezembro de 2019.

MARINI, R. M. Memoria. Disponível em: <http://www.marini-escritos.unam.mx>. Acesso 
em: maio 2017. (Data da publicação não divulgada).

MARINI, R. M. Subdesarrollo y revolución en América Latina. 1968. Disponível em: <http:// www.marini-escritos.unam.mx/>. Acesso em: dezembro de 2019.

MARINI, R. M. Subdesarrollo y revolución. México: Siglo XXI, 1974.

MARINI, R. M. Subdesenvolvimento e revolução. Trad. Fernando Correa Prado e Marina Machado Gouvêa. Florianópolis: Insular. Instituto de Estudos Latino-Americanos (IELA), 2012a. (Coleção Pátria Grande).

MARINI, R. M. El subimperialismo brasileño. Santiago, Chile: Centro de Estudios Socio-Económicos - Facultad de Ciencias Económicas/Universidad del Chile, 1971.

MOTA FILHO, A. V. B. Breve análise da teoria do subimperialismo brasileiro. Cadernos CERU, série 2, v. 28, n. 2, dez. 2017.

SANTOS, T. Dependencia y cambio social. Buenos Aires: Amorrortu, 1973.

SANTOS, T. Socialismo o facismo: el nuevo caractér de la dependencia y el dilema latino americano. México: Edicol, 1978.

SILVA, H. C. M. da Deterioração dos termos de intercâmbio, substituição de importações, industrialização e substituição de exportações: a política de comércio exterior brasileira de 1945 a 1979. Revista Brasileira de Política Internacional, n. 46 (1), pp. 39-65, 2003.

SOUZA, C. L. S. Cooperação antagônica e a dupla articulação dependente: a dinâmica da luta de classes no Brasil. Temporalis, ano 17, n. 34, jul./dez. 2017.

\section{Sobre o autor}

Pedro Henrique Evangelista Duarte - pheduarte@ufg.br

Faculdade de Administração, Ciências Contábeis e Economia, Universidade Federal de Goiás, Goiânia, GO, Brasil. ORCID: https://orcid.org/0000-0002-2169-4617.

\section{Sobre $o$ artigo}

Recebido em 09 de outubro de 2019. Aprovado em 12 de junho de 2020. 